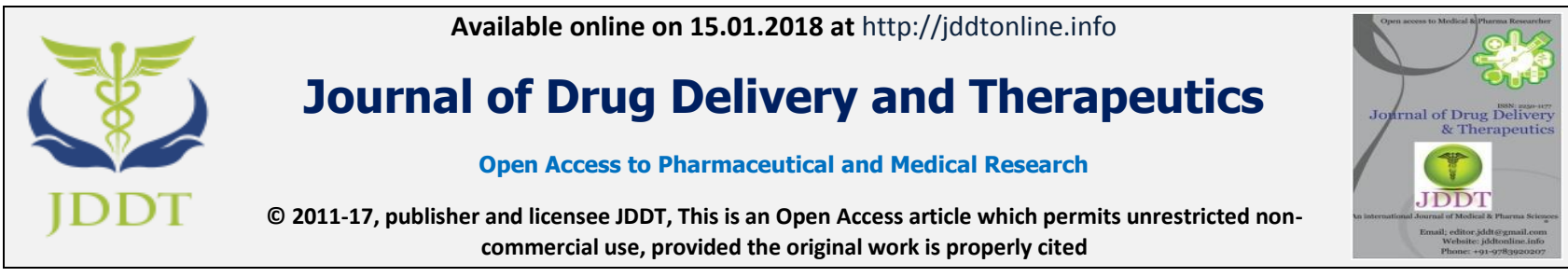

Open $\odot$ Access

Research Article

\title{
OPTIMIZATION OF THE RELEASE KINETICS OF DILTIAZEM HYDROCHLORIDE FROM TABLETED MICROSPHERES
}

\author{
Manish Kumar Gupta ${ }^{1}$, Alok Khunteta ${ }^{2}$, \\ ${ }^{1}$ Professor and Principal, Jaipur College of Pharmacy, Jaipur, Rajasthan, India \\ ${ }^{2}$ Associate Professor, LBS College of Pharmacy, Jaipur, Rajasthan, India
}

\section{ABSTRACT}

Formulation $\mathrm{F}_{5}, \mathrm{~F}_{6}, \mathrm{~F}_{7}$ and $\mathrm{F}_{8}$ were selected to make the tablets because of their high percentage release (more than $90 \%$ ). $500 \mathrm{mg}$ weight of tablets containing $120 \mathrm{mg}$ strength of Diltiazem hydrochloride were prepared from formulations $\mathrm{F}_{5}, \mathrm{~F}_{6}, \mathrm{~F}_{7}$ and $\mathrm{F}_{8}$. release of Diltiazem hydrochloride at different interval of time: $1 \mathrm{hr}, 4 \mathrm{hrs}, 8 \mathrm{hrs}$ and $12 \mathrm{hrs}$ for different formulations, it can be concluded that more than $90 \%$ of Diltiazem hydrochloride was released from formulations $F_{1}, F_{3}, F_{5}, F_{6}, F_{7}, F_{8}, F_{9}, F_{11}$ at 12 hours. After compaction into the tableted form, the dissolution or release of the drug will reduce. Hence, these formulations may be compressed into the tablet forms so that the release should be around or more than $80 \%$. Some analytical definitions of the $Q(t)$ function are commonly used, such as zero order, first order, Higuchi, Korsmeyer-Peppas, Hixson-Crowell models, Weibull model, Baker Lonsdale model, Hopfenberg model, etc. These models are used to characterize drug dissolution/release profiles.

Keywords: Optimization, Microsphere, Diltiazem hydrochloride, Higuchi, Korsmeyer-Peppas, Hixson-Crowell models.

Article Info: Received 11 Nov, 2017; Review Completed 08 Jan, 2018; Accepted 09 Jan, 2018; Available online 15 Jan, 2018

\section{Cite this article as:}

Gupta MK, Khunteta A, Optimization of the release kinetics of diltiazem hydrochloride from tableted microspheres, Journal of Drug Delivery and Therapeutics. 2018; 8(1):57-63

DOI: $\underline{\text { http://dx.doi.org/10.22270/iddt.v8i1.1551 }}$

*Address for Correspondence

Dr. Manish Kumar Gupta, Professor and Principal, Jaipur College of Pharmacy, Jaipur, Rajasthan, India

\section{INTRODUCTION}

The concept of drug delivery has been revolutionized with the advancement in drug delivery systems, especially those offering a sustained and controlled action of drug to desired area of effect ${ }^{1}$.

Microsponges are polymeric delivery systems composed of porous microspheres. They are tiny sponge-like spherical particles with a large porous surface. Moreover, they may enhance stability, reduce side effects and modify drug release favorably.

The term microparticles refer to a particle with a diameter of $1-1000 \mu \mathrm{m}$, irrespective of the precise interior or exterior structure. ${ }^{2}$ Microsponges are polymeric delivery systems composed of porous microspheres. They are tiny sponge-like spherical particles with a large porous surface. Moreover, they may enhance stability, reduce side effects and modify drug release favorably ${ }^{3}$.

Microspheres usually have diffusion controlled release profiles with a permanent release rate that is controlled kinetically by the particle size, whereas microcapsules usually have diffusion or dissolution controlled release profiles or both. Microcapsules expel their content by a single high burst as the shell breaks or slow releases.

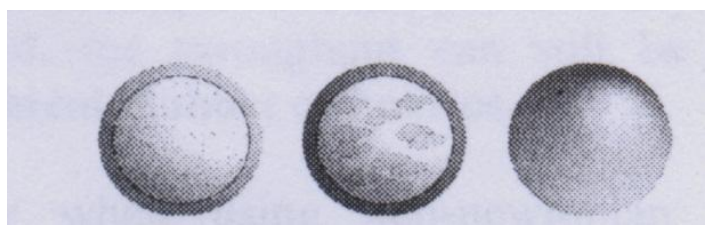

Figure 1: microsphere

Hard gelatin capsules are very elegant dosage forms, but have the disadvantages of higher production cost, lower 
production rate and tampering potential when compared to compressed tablets. Microspheres have been tableted to control or modify the release of the drug. The tablet manufacturing process from microspheres will create a single unit from a multi-particulate system in order to produce compact forms that disintegrate into many subunits soon after ingestion to attain more uniform concentrations of the drug in the body. Reduced risk of tampering, higher dose strength per unit and higher production rate of the tablet process can be listed among the advantages of tabletting ${ }^{4}$

\section{METHODS}

Optimization of below given formulation:

Table 1: Formulations of Diltiazem hydrochloride loaded Microspheres prepared with different Polymers and Polymer mixtures (Drug: Polymer $=1: 1$ )

\begin{tabular}{|l|l|l|l|l|l|l|l|l|}
\hline Contents of Formulations & $\mathbf{F}_{\mathbf{1}}$ & $\mathbf{F}_{\mathbf{2}}$ & $\mathbf{F}_{\mathbf{3}}$ & $\mathbf{F}_{\mathbf{4}}$ & $\mathbf{F}_{\mathbf{5}}$ & $\mathbf{F}_{\mathbf{6}}$ & $\mathbf{F}_{\mathbf{7}}$ & $\mathbf{F}_{\mathbf{8}}$ \\
\hline Diltiazem hydrochloride(gm) & 2.0 & 2.0 & 2.0 & 2.0 & 2.0 & 2.0 & 2.0 & 2.0 \\
\hline Eudragit RL 100 (gm) & 2.0 & - & - & - & 1.0 & - & 1.0 & - \\
\hline Eudragit RS 100 (gm) & - & 2.0 & - & - & 1.0 & - & - & 1.0 \\
\hline Eudragit RLPO (gm) & - & - & 2.0 & - & - & 1.0 & - & 1.0 \\
\hline Eudragit RSPO (gm) & - & - & - & 2.0 & - & 1.0 & 1.0 & - \\
\hline $\begin{array}{l}\text { Magnesium Stearate (gm) } \\
\text { Dispersing Agent) }\end{array}$ & 0.300 & 0.300 & 0.300 & 0.300 & 0.300 & 0.300 & 0.300 & 0.300 \\
\hline Methanol (ml) & 3.0 & 3.0 & 3.0 & 3.0 & 3.0 & 3.0 & 3.0 & 3.0 \\
\hline Acetone (ml) & 7.0 & 7.0 & 7.0 & 7.0 & 7.0 & 7.0 & 7.0 & 7.0 \\
\hline Liquid paraffin (ml) & 100 & 100 & 100 & 100 & 100 & 100 & 100 & 100 \\
\hline Drug : Polymer & $1: 1$ & $1: 1$ & $1: 1$ & $1: 1$ & $1: 1$ & $1: 1$ & $1: 1$ & $1: 1$ \\
\hline Magnesium Stearate (\%) & 3 & 3 & 3 & 3 & 3 & 3 & 3 & 3 \\
\hline
\end{tabular}

Table 2: Formulations of Diltiazem hydrochloride loaded Microspheres prepared with different Polymers and Polymer mixtures (Drug: Polymer =1:2)

\begin{tabular}{|l|l|l|l|l|l|l|l|l|}
\hline Contents of Formulations & $\mathbf{F}_{\mathbf{9}}$ & $\mathbf{F}_{\mathbf{1 0}}$ & $\mathbf{F}_{\mathbf{1 1}}$ & $\mathbf{F}_{\mathbf{1 2}}$ & $\mathbf{F}_{\mathbf{1 3}}$ & $\mathbf{F}_{\mathbf{1 4}}$ & $\mathbf{F}_{\mathbf{1 5}}$ & $\mathbf{F}_{\mathbf{1 6}}$ \\
\hline Diltiazem hydrochloride (gm) & 2.0 & 2.0 & 2.0 & 2.0 & 2.0 & 2.0 & 2.0 & 2.0 \\
\hline Eudragit RL 100 (gm) & 4.0 & - & - & - & 2.0 & - & 2.0 & - \\
\hline Eudragit RS 100 (gm) & - & 4.0 & - & - & 2.0 & - & - & 2.0 \\
\hline Eudragit RLPO (gm) & - & - & 4.0 & - & - & 2.0 & - & 2.0 \\
\hline Eudragit RSPO (gm) & - & - & - & 4.0 & - & 2.0 & 2.0 & - \\
\hline $\begin{array}{l}\text { Magnesium Stearate (gm) } \\
\text { (Dispersing Agent) }\end{array}$ & 0.600 & 0.600 & 0.600 & 0.600 & 0.600 & 0.600 & 0.600 & 0.600 \\
\hline Methanol (ml) & 6.0 & 6.0 & 6.0 & 6.0 & 6.0 & 6.0 & 6.0 & 6.0 \\
\hline Acetone (ml) & 14.0 & 14.0 & 14.0 & 14.0 & 14.0 & 14.0 & 14.0 & 14.0 \\
\hline Liquid paraffin (ml) & 200 & 200 & 200 & 200 & 200 & 200 & 200 & 200 \\
\hline Drug : Polymer & $1: 2$ & $1: 2$ & $1: 2$ & $1: 2$ & $1: 2$ & $1: 2$ & $1: 2$ & $1: 2$ \\
\hline Magnesium Stearate (\%) & 3 & 3 & 3 & 3 & 3 & 3 & 3 & 3 \\
\hline
\end{tabular}

\section{Optimization of release rate}

After observing the release of Diltiazem hydrochloride at different interval of time: $1 \mathrm{hr}, 4 \mathrm{hrs}, 8 \mathrm{hrs}$ and $12 \mathrm{hrs}$ for different formulations, it can be concluded that more than $90 \%$ of Diltiazem hydrochloride was released from formulations $\mathrm{F}_{1}, \mathrm{~F}_{3}, \mathrm{~F}_{5}, \mathrm{~F}_{6}, \mathrm{~F}_{7}, \mathrm{~F}_{8}, \mathrm{~F}_{9}, \mathrm{~F}_{11}$ at 12 hours. 
After compaction into the tableted form, the dissolution or release of the drug will reduce. Hence, these formulations may be compressed into the tablet forms so that the release should be around or more than $80 \%$.

\section{Co-relation between particle size and in-vitro release}

The particle size in mean diameters along with their cumulative percent release is tabulated below;

Table 3: Correlation between mean particle size and in-vitro release of microspheres

\begin{tabular}{|l|l|l|l|}
\hline Formulation & Drug: Polymer ratio & $\begin{array}{l}\text { Mean Particle size } \\
(\mu \mathrm{m})\end{array}$ & $\begin{array}{l}\text { Cumulative \% Drug } \\
\text { released at 12 hrs }\end{array}$ \\
\hline $\mathrm{F}_{5}$ & & 243.75 & 93.85 \\
$\mathrm{~F}_{6}$ & $1: 1$ & 230.25 & 94.98 \\
$\mathrm{~F}_{7}$ & & 206.00 & 94.24 \\
$\mathrm{~F}_{8}$ & 212.25 & 97.53 \\
\hline $\mathrm{F}_{13}$ & & 354.75 & 72.75 \\
$\mathrm{~F}_{14}$ & $1: 2$ & 359.00 & 66.23 \\
$\mathrm{~F}_{15}$ & & 370.75 & 66.72 \\
$\mathrm{~F}_{16}$ & & 334.00 & 67.41 \\
\hline
\end{tabular}

Hence from the above result, it can be concluded that as the particle size of the microspheres increased, the release rate of Diltiazem hydrochloride decreased. Hence, particle size of microsphere is inversely proportional to the release of drug from microspheres. It can be explained on the basis, that as the polymer amount increases, the matrix wall of microspheres become thicker. The formation of a thick wall lead to slower dissolution rate of drug caused by longer diffusional path.

\section{Tableting of Microspheres}

Formulation $\mathrm{F}_{5}, \mathrm{~F}_{6}, \mathrm{~F}_{7}$ and $\mathrm{F}_{8}$ were selected to make the tablets because of their high percentage release (more than 90\%). $500 \mathrm{mg}$ weight of tablets containing $120 \mathrm{mg}$ strength of Diltiazem hydrochloride was prepared from formulations $\mathrm{F}_{5}, \mathrm{~F}_{6}, \mathrm{~F}_{7}$ and $\mathrm{F}_{8}$. Microspheres along with excipients - lactose monohydrate, microcrystalline cellulose and sodium starch glycolate as disintegrant were compressed into tablets using single stroke tablet machine.

\section{In - vitro Dissolution of tableted microspheres}

Compaction of drug loaded microparticulate powders into tablets have been reported as useful therapeutic approach for oral administration of controlled release formulations. With respect to free powder, tablets can give more reproducible drug delivery and biopharmaceutical response, as well as a better patient compliance.

The release data of Diltiazem hydrochloride from tableted microspheres are shown in Figure. The in-vitro release profile of tableted microspheres indicated that the release of the drug was slow than that of microspheres. The release increased gradually and up to $12 \mathrm{hrs}$, more than $85 \%$ of drug was into the medium from tableted formulations $\left(\mathrm{TF}_{5}, \mathrm{TF}_{6}, \mathrm{TF}_{7}\right.$ and $\left.\mathrm{TF}_{8}\right)$. As the initial burst release of drug was observed in microspheres $\left(\mathrm{F}_{5}, \mathrm{~F}_{6}, \mathrm{~F}_{7}\right.$ and $\left.\mathrm{F}_{8}\right)$. However, tableting of the microparticulate systems can overcome the disadvantage of such initial large 'burst' release.

Table 4: Cumulative release of Diltiazem hydrochloride from tableted microsphere

\begin{tabular}{|c|c|c|c|c|c|c|}
\hline \multirow[b]{2}{*}{ Formulation } & \multirow[b]{2}{*}{ Composition } & \multirow{2}{*}{$\begin{array}{l}\text { Drug: } \\
\text { Polymer } \\
\text { Ratio } \\
\end{array}$} & \multicolumn{4}{|c|}{ Cumulative \% Release of Diltiazem hydrochloride } \\
\hline & & & $1 \mathrm{hrs}$ & $4 \mathrm{hrs}$ & $8 \mathrm{hrs}$ & $12 \mathrm{hrs}$ \\
\hline $\mathrm{Tab} \mathrm{F}_{5}$ & $\begin{array}{l}\text { RL100 : } \\
\text { RS100 }\end{array}$ & \multirow{4}{*}{ 1: 1} & 5.16 & 25.53 & 65.28 & 91.18 \\
\hline $\mathrm{TabF}_{6}$ & RLPO : RSPO & & 6.94 & 30.10 & 61.59 & 88.18 \\
\hline $\mathrm{Tab} \mathrm{F}_{7}$ & RL100 : RSPO & & 5.92 & 27.93 & 63.43 & 89.59 \\
\hline $\mathrm{Tab} \mathrm{F}_{8}$ & RS100 : RLPO & & 8.08 & 32.11 & 66.31 & 86.35 \\
\hline
\end{tabular}

The dissolution profiles of Formulation TabF5, TabF6, TabF7, and TabF8 were analyzed statistically by ANOVA.

Table 5: Comparison of dissolution profiles of Formulation TabF5, TabF6, TabF7, and TabF8 using one way ANOVA

\begin{tabular}{|l|l|l|l|l|c|}
\hline \multirow{2}{*}{ Formulations } & \multicolumn{4}{|c|}{ Calculated values of ' $\mathrm{F}$ ' } & $\begin{array}{c}\text { Table value } \\
\left(\mathrm{F}_{0.05}\right)^{*}\end{array}$ \\
\cline { 2 - 5 } & $1^{\text {st }}$ hour & $4^{\text {th }}$ hour & $8^{\text {th }}$ hour & $12^{\text {th }}$ hour & \multirow{2}{*}{4.0662} \\
\hline TabF5, TabF6, TabF7, and TabF8 & 2.136 & 1.928 & 2.025 & 2.632 & \\
\hline
\end{tabular}

$*$ D.F. $=$ Degree of freedom $=(3,8)$ 
From the ANOVA test it was found that there was no significant difference among the Formulation TabF5, TabF6, TabF7, and TabF8 at the time of $1 \mathrm{hr}, 4 \mathrm{hr}, 8 \mathrm{hr}$ and $12 \mathrm{hr}$. This is because all the tablets contained the microspheres of combination of Eudragit RL and RS type.

\section{Comparison of In-vitro Dissolution of microspheres and tableted microspheres}

The dissolution profiles of microspheres and tableted microspheres were analyzed statistically by student- $t$ test.

Table 6: Comparison of dissolution profiles of microspheres and tableted microspheres using student-t test

\begin{tabular}{|l|l|l|l|l|c|}
\hline \multirow{2}{*}{ Formulations } & \multicolumn{3}{|l|}{ Calculated values of ' $\mathrm{t}$ ' } & $\begin{array}{c}\text { Table value } \\
\left(\mathrm{t}_{0.05}\right)^{*}\end{array}$ \\
\cline { 2 - 5 } & $1^{\text {st }}$ hour & $4^{\text {th }}$ hour & $8^{\text {th }}$ hour & $12^{\text {th }}$ hour & \\
\hline F5 - TabF5 & 5.328 & 14.79 & 1.440 & 2.023 & \\
\hline F6 - TabF6 & 4.345 & 13.784 & 1.687 & 1.973 & \multirow{2}{*}{2.132} \\
\hline F7 - TabF7 & 7.750 & 19.528 & 1.878 & 1.118 & 1.312 \\
\hline F8 - TabF8 & 5.161 & 16.81 & 1.940 & 13 & \\
\hline
\end{tabular}

From the student-t test it was found that there was a significant difference between dissolution profiles of microspheres and tableted microspheres from 1-4 hours. But there was not any significant difference between these for the 8-12 hours.

Two reasons can be attributed to this reason:

First, tableting of microspheres reduces the initial burst release of the drug from the formulation.

Second, it is clear from the mathematical models, that the release of Diltiazem hydrochloride from microspheres F5 - F8 follows anomalous transport $(\mathrm{n}=$ between 0.5 - 1.0 for Peppas model, that corresponds to diffusion, erosion and swelling mechanism or mixed order kinetics). Whereas, formulation TabF6 and Tab F8 follow zero order kinetics ( $\mathrm{n} \approx 1$ for Peppas model), and formulation TabF5 and TabF7 follow case - II transport ( $\mathrm{n}>1$ for Peppas model, that correspond to erosion and relaxation of swollen polymer). So, there is significant difference from the student- $t$ test it was found that there was a significant difference between dissolution profiles of microspheres and tableted microspheres from 1-4 hours.

\section{Mathematical model: ${ }^{5}$}

Several theories and kinetic models describe the dissolution of drug from immediate release and modified release dosage forms. There are several models to represent the drug dissolution profiles where $f(t)$ is a function of time related to the amount of drug dissolved from the pharmaceutical dosage form.

The quantitative interpretation of the values obtained in the dissolution assay is facilitated by the usage of generic equation that translates the dissolution curve, function of some parameters related with the pharmaceutical dosage forms. Drug dissolved from solid dosage forms has been described by kinetic models in which the dissolved amount of drug (Q) is a function of the test time, $t$ or $Q(t)$. Some analytical definitions of the $\mathrm{Q}(\mathrm{t})$ function are commonly used, such as zero order, first order, Higuchi, Korsmeyer-Peppas, Hixson-Crowell models, Weibull model, Baker - Lonsdale model, Hopfenberg model, etc. These models are used to characterize drug dissolution/release profiles.

\section{(a) Zero Order Kinetics}

This model represents an ideal release profile in order to achieve the pharmacological prolonged action. Zero order release constitutes drug release from the dosage form that is independent of the amount of drug in the delivery system (that is, a constant release rate).

The following equation is used to express the model:

$$
\mathbf{Q}_{\mathrm{t}}=\mathbf{Q}_{\mathrm{o}}+\mathbf{K}_{\mathrm{o}} \mathbf{t}
$$

Where $Q_{t}$ is the amount of drug dissolved in time $t$

$\mathrm{Q}_{\mathrm{o}}$ is the initial amount of drug in the solution

$\mathrm{K}_{\mathrm{o}}$ is the zero order release constant

For practical purposes the equation is rearranged:

\section{Percent drug released $=\mathrm{Kt}$}

This is applicable to dosage forms like transdermal systems, coated dosage forms, osmotic systems as well as matrix tablets with low soluble drugs.

\section{(b) First Order Kinetics}

First order release constitutes drug release in a way that is proportional to the amount of drug remaining in its interior; in such a way that amount of drug released by unit time diminish.

The following equation is used to express the model:

$$
\log Q_{t}=\log Q_{0}+K t / 2.303
$$

Where $Q_{t}$ is the amount of drug dissolved in time $t$

$\mathrm{Q}_{\mathrm{o}}$ is the initial amount of drug in the solution

$$
\mathrm{K} \text { is the first order release constant }
$$

For practical purposes the equation is rearranged:

$$
\log \% \text { of drug unreleased }=\mathrm{Kt} / \mathbf{2 . 3 0 3}
$$

This model is applicable to dosage forms such as those containing water-soluble drugs in porous matrices.

\section{(c) Higuchi Model}

Higuchi describes drug release as a diffusion process based in Fick's law, square root dependent.

The following equation is used to express the model: 


$$
Q_{t}=K_{h} t^{1 / 2}
$$

Where $Q_{t}$ is the amount of drug dissolved in time $t$

$\mathrm{K}_{\mathrm{h}}$ is the first order release constant

For practical purposes the equation is rearranged:

$$
\text { Percent drug released }=\mathrm{Kt}^{1 / 2}
$$

This model is applicable to systems with drug dispersed in uniform swellable polymer matrix as in case of matrix tablets with water soluble drugs.

\section{(d) Korsmeyer - Peppas Model}

This model is widely used when the release mechanism is not well known or when more than one type of release phenomenon could be involved

The following equation is used to express the model

$$
\mathbf{Q}_{\mathbf{t}} / \mathbf{Q}_{\infty}=\mathrm{Kt}^{\mathbf{n}}
$$

Where $\mathrm{Q}_{\mathrm{t}}$ is the amount of drug dissolved in time $\mathrm{t}$

$\mathrm{Q}_{\infty}$ is the amount of drug dissolved in infinite time

$\mathrm{n}$ is the release exponent indicative of drug release mechanism

$$
\mathrm{K} \text { is the kinetic constant }
$$

For practical purposes the equation is rearranged

\section{Log percent drug released $=\log K+n \log t$}

Peppas used $n$ value in order to characterize different release mechanism concluding for values of $n=0.5$ for
Fickian diffusion and values of $\mathrm{n}$, between 0.5 to 1.0 for anomalous transport (corresponds to diffusion, erosion and swelling mechanism or mixed order kinetics) and higher values of $n, n=1$ (zero order release) or $n>1$ for case-II transport (corresponds to erosion and relaxation of swollen polymer layer).

\section{(e) Hixson - Crowell Model}

Hixson and Crowel recognizing that the particle regular area is proportional to the cubic root of its volume, derived an equation that can be described in the following manner:

$$
\left(W_{0}\right)^{1 / 3}-\left(W_{t}\right)^{1 / 3}=K_{s} t
$$

Where: $\mathrm{W}_{0}$ - is the initial amount of drug in the dosage form

$\mathrm{W}_{\mathrm{t}}$ - is the remaining amount of drug in the dosage form at time $\mathrm{t}$

$\mathrm{K}_{\mathrm{s}}$ - is a constant incorporating the surface- volume relationship

For practical purposes the equation is rearranged

$$
(\% \text { Drug Unreleased })^{1 / 3}=\mathbf{K t}
$$

This model has been used to describe the release profile keeping in mind the diminishing surface of the drug

\begin{tabular}{|c|c|c|c|c|c|c|c|c|c|}
\hline Model & Statistics & F1 & $\mathrm{F} 2$ & F3 & F4 & F5 & F6 & F7 & F8 \\
\hline & $\mathrm{r}^{2}$ & 0.7793 & 0.9280 & 0.7851 & 0.9007 & 0.9157 & 0.8817 & 0.9085 & 0.8542 \\
\hline Zero & $\mathrm{p}$ & $<0.01$ & $<0.001$ & $<0.01$ & $<0.001$ & $<0.001$ & $<0.001$ & $<0.001$ & $<0.001$ \\
\hline \multirow[t]{2}{*}{ Order } & slope & 9.0430 & 4.5115 & 9.0159 & 4.5087 & 7.3090 & 7.2048 & 7.0346 & 6.9798 \\
\hline & $\mathrm{K}$ & 9.0430 & 4.5115 & 9.0159 & 4.5087 & 7.3090 & 7.2048 & 7.0346 & 6.9797 \\
\hline \multirow{4}{*}{$\begin{array}{l}\text { First } \\
\text { Order }\end{array}$} & $\mathrm{r}^{2}$ & 0.9197 & 0.9747 & 0.9518 & 0.9598 & 0.9934 & 0.9972 & 0.9880 & 0.9697 \\
\hline & $\mathrm{p}$ & $<0.001$ & $<0.001$ & $<0.001$ & $<0.001$ & $<0.001$ & $<0.001$ & $<0.001$ & $<0.001$ \\
\hline & slope & -0.2115 & -0.0332 & -0.1853 & -0.0343 & -0.0983 & -0.1059 & -0.0984 & -0.1183 \\
\hline & $\mathrm{K}$ & 0.4871 & 0.0765 & 0.4268 & 0.0790 & 0.2264 & 0.2439 & 0.2266 & 0.2725 \\
\hline \multirow{4}{*}{$\begin{array}{l}\text { Higuchi } \\
\text { Model }\end{array}$} & $\mathrm{r}^{2}$ & 0.9590 & 0.9914 & 0.9619 & 0.9854 & 0.9888 & 0.9839 & 0.9951 & 0.9807 \\
\hline & $\mathrm{p}$ & $<0.001$ & $<0.001$ & $<0.001$ & $<0.001$ & $<0.001$ & $<0.001$ & $<0.001$ & $<0.001$ \\
\hline & slope & 32.777 & 18.017 & 32.610 & 18.221 & 29.346 & 29.406 & 28.445 & 28.895 \\
\hline & $\mathrm{K}$ & 32.777 & 18.017 & 32.610 & 18.221 & 29.346 & 29.406 & 28.445 & 28.895 \\
\hline \multirow{4}{*}{$\begin{array}{l}\text { Peppas } \\
\text { Model }\end{array}$} & $\mathrm{r}^{2}$ & 0.9604 & 0.9894 & 0.9644 & 0.9795 & 0.9764 & 0.9660 & 0.9863 & 0.9576 \\
\hline & $\mathrm{p}$ & $<0.001$ & $<0.001$ & $<0.001$ & $<0.001$ & $<0.001$ & $<0.001$ & $<0.001$ & $<0.001$ \\
\hline & $\mathrm{n}$ & 0.3810 & 0.4773 & 0.3845 & 0.4485 & 0.6427 & 0.5884 & 0.5525 & 0.5180 \\
\hline & $\mathrm{K}$ & 45.384 & 18.858 & 44.679 & 20.951 & 21.009 & 24.536 & 25.416 & 29.174 \\
\hline
\end{tabular}
particles during the dissolution. After fitting into these models, the selection was based on the comparison of higher determination coefficient $\left(\mathrm{r}^{2}\right)$.

Table 7 (i): Descriptive statistics of regression and other parameters of the mathematical models for the dissolution data of formulations F1 - F8 
Table 7 (ii): Descriptive statistics of regression and other parameters of the mathematical models for the dissolution data of formulations F9 - F16

\begin{tabular}{|l|l|l|l|l|l|l|l|l|l|}
\hline Model & Statistics & F9 & F10 & F11 & F12 & F13 & F14 & F15 & F16 \\
\hline & $\mathrm{r}^{2}$ & 0.8631 & 0.9623 & 0.8234 & 0.9589 & 0.9891 & 0.9823 & 0.9957 & 0.9898 \\
Zero & $\mathrm{p}$ & $<0.001$ & $<0.001$ & $<0.001$ & $<0.001$ & $<0.001$ & $<0.001$ & $<0.001$ & $<0.001$ \\
Order & $\mathrm{slope}$ & 6.6277 & 4.0604 & 6.7626 & 4.2313 & 5.5202 & 4.8933 & 5.1454 & 5.1415 \\
& $\mathrm{~K}$ & 6.6277 & 4.0604 & 6.7626 & 4.2313 & 5.5202 & 4.8933 & 5.1454 & 5.1415 \\
\hline & $\mathrm{r}^{2}$ & 0.9957 & 0.9878 & 0.9952 & 0.9899 & 0.9459 & 0.9759 & 0.9656 & 0.9786 \\
First & $\mathrm{p}$ & $<0.001$ & $<0.001$ & $<0.001$ & $<0.001$ & $<0.001$ & $<0.001$ & $<0.001$ & $<0.001$ \\
Order & $\mathrm{slope}$ & -0.0848 & -0.0265 & -0.1004 & -0.0281 & -0.0415 & -0.0349 & -0.0358 & -0.0370 \\
& $\mathrm{~K}$ & 0.1953 & 0.0610 & 0.2312 & 0.0647 & 0.0956 & 0.0804 & 0.0825 & 0.0852 \\
\hline & $\mathrm{r}^{2}$ & 0.9838 & 0.9821 & 0.9674 & 0.9897 & 0.9280 & 0.9645 & 0.9321 & 0.9584 \\
Higuchi & $\mathrm{p}$ & $<0.001$ & $<0.001$ & $<0.001$ & $<0.001$ & $<0.001$ & $<0.001$ & $<0.001$ & $<0.001$ \\
Model & $\mathrm{slope}$ & 27.339 & 15.849 & 28.320 & 16.609 & 20.660 & 18.734 & 19.244 & 19.548 \\
& $\mathrm{~K}$ & 27.339 & 15.849 & 28.320 & 16.609 & 20.660 & 18.734 & 19.244 & 19.548 \\
\hline & $\mathrm{r}^{2}$ & 0.9632 & 0.9687 & 0.9402 & 0.9898 & 0.9796 & 0.9877 & 0.9866 & 0.9916 \\
Peppas & $\mathrm{p}$ & $<0.001$ & $<0.001$ & $<0.001$ & $<0.001$ & $<0.001$ & $<0.001$ & $<0.001$ & $<0.001$ \\
Model & $\mathrm{n}$ & 0.5223 & 0.5325 & 0.5098 & 0.5584 & 0.7326 & 0.6337 & 0.7793 & 0.6931 \\
& $\mathrm{~K}$ & 27.146 & 13.807 & 29.655 & 13.782 & 10.371 & 12.451 & 8.640 & 11.138 \\
\hline
\end{tabular}

* For Zero order, First order, Higuchi Model:n= 13 (For formulation F2, F4 - F16) n= 10 (For formulation F1, F3)

\# For Peppas Model: $n=12$ (For formulation F2, F4 - F16) n= 9 (For formulation F1, F3)

Table 7(iii): Descriptive statistics of regression and other parameters of the mathematical models for the dissolution data of formulations TabF5 - TabF8

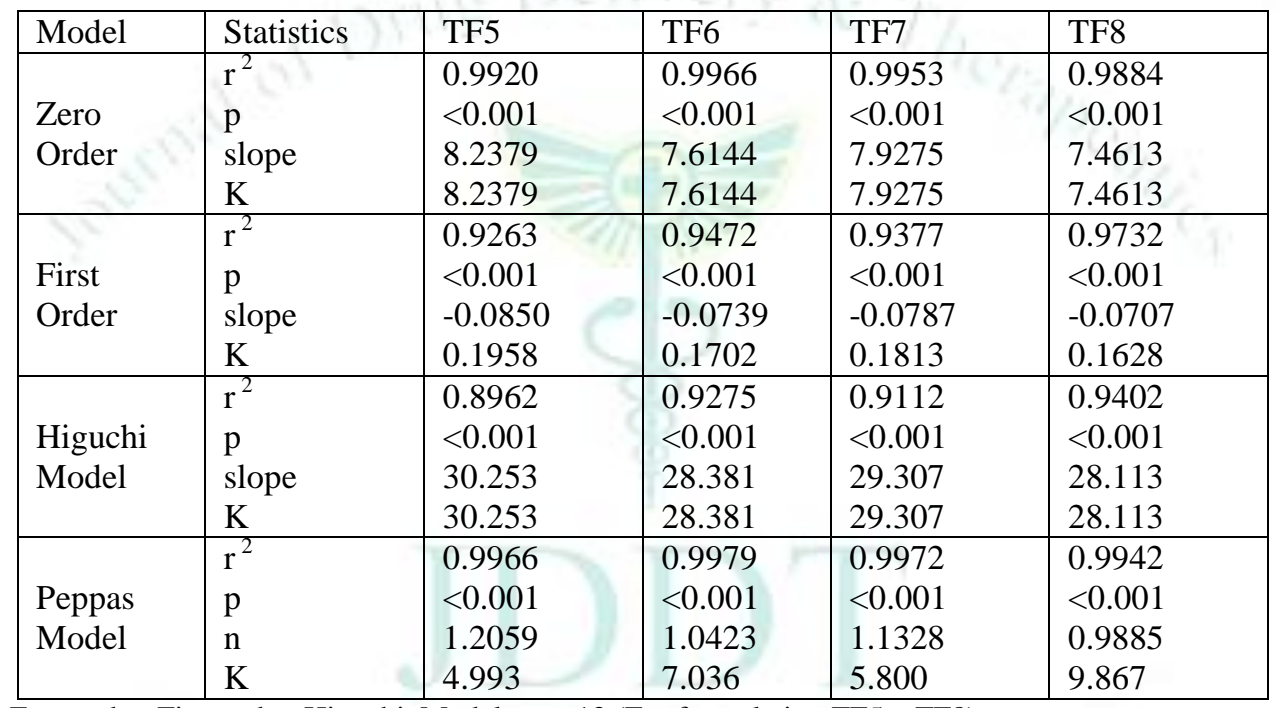

* For Zero order, First order, Higuchi, Model: $\mathrm{n}=13$ (For formulation TF5 - TF8)

\# For Peppas Model: $n=12$ (For formulation TF5 - TF8)

\section{Accelerated stability study}

Formulations $\mathrm{F}_{5}, \mathrm{~F}_{6}, \mathrm{~F}_{7}$ and $\mathrm{F}_{8}$ were stored in glass bottle, after wrapping with aluminium foil, at $40^{\circ} \mathrm{C}$ in humidity controlled oven for 3 periods of months. It was observed that there was no change in the morphology of microspheres, as well as no agglomerates were formed. The percentage residual drug content of microspheres were found to be $98.86 \%$ for $\mathrm{F}_{5} ; 98.65 \%$ for $\mathrm{F}_{6} ; 98.72 \%$ for $\mathrm{F}_{7}$ and $98.36 \%$ for $\mathrm{F}_{8}$ after storage for 3 months as compared to initial $100 \%$ content

\section{CONCLUSION}

It is observed from the table that the determination coefficient $\left(\mathrm{r}^{2}\right)$ of formulations F2, F4 - F16 and TabF5 TabF8 was significant for zero-order. Similarly, the determination co-efficient $\left(r^{2}\right)$ of formulations F1-F16 and TabF5-TabF8 for first order kinetics was also showing the significant correlation.
For Higuchi model, the determination co-efficient $\left(\mathrm{r}^{2}\right)$ of formulations F1-F16 and TabF5-TabF8 are significant. Hence, all were following Higuchi model.

Peppas model is used when the release mechanism is not well known or when more than one type of release phenomenon could be involved. It indicates the diffusional release mechanisms from polymeric films. The determination co-efficient $\left(\mathrm{r}^{2}\right)$ of formulations F1F16 and TabF5-TabF8 are significant.

Here, in case of formulations F5-F8, the value of $n$ was between 0.5-1.0, indicating release kinetics involves anomalous transport (that corresponds to diffusion, erosion and swelling mechanism or mixed order kinetics). Also for formulations TF5 and TF7, the value of $\mathrm{n}$ was $>1$, indicating that the release kinetics followed case - II transport (corresponds to erosion and relaxation of swollen polymer). 
But for formulation TF6 and TF8, the value of $\mathrm{n}$ is $\approx 1$, indicating that the release kinetics followed zero - order release.

Also the value of $\mathrm{r}^{2}$ for TF5, TF6, TF7 and TF8 are maximum for zero order (among zero order, first order

\section{REFERENCES}

1. Rastogi V, Shukla S, Singh R, Lal N, Yadav P. Microspheres: a promising drug carrier. Journal of Drug Delivery and Therapeutics, 2016; 6(3):18-26. doi:10.22270/jddt.v6i3.1196

2. Benoit JP, Marchais H, Rolland H, Velde VV. Biodegradabla microspheres: advances in production technology. In: Benita, S. (Ed.), Microencapsulation Methods and Industrial Applications. Marcel Dekker, New York, 1996, pp. 35-72.

3. Kappor D, Patel M, Vyas R, Lad C, Tyagi B. A review on microsponge drug delivery system. Journal of Drug Delivery and Higuchi model), indicating that the release of Diltiazem hydrochloride from these tablets followed zero order kinetics.

and Therapeutics, 2014; 4(5):29-35.

doi:10.22270/jddt.v4i5.978.

4. Sengel CT, Hascicek C, Gonul N. Development and in-vitro evaluation of modified release tablets including ethylcellulose microspheres loaded with diltiazem hydrochloride. J. Microencapsul. 2006; 23:135-152.

5. Costa P, Lobo JMS. Modeling and comparison of dissolution profiles. Eur. J. Pharm. Sci. 2001; 13:123-133. 